\title{
Perinatal outcomes of monochorionic diamniotic triplet pregnancies: a case series
}

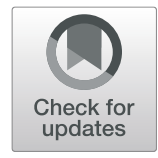

Tingting $X u^{1,2}$, Xiaodong Wang ${ }^{1,2}$, Haiyan $Y u^{1,2^{*}}$ (D) and Xinghui Liu ${ }^{1,2}$

\begin{abstract}
Background: Triplet pregnancies are associated with higher fetal morbidity and mortality rates as well as lifethreatening maternal complications. Monochorionic diamniotic (MCDA) triplet pregnancies are very rare compared to other types of triplet pregnancies.

Case presentation: We report three cases of MCDA triplet pregnancies between January 2012 and December 2017. Two of these MCDA triplet pregnancies received regular and intensive prenatal care, were diagnosed by ultrasonography during the first trimester or early second trimester, and had good perinatal outcomes. The case with irregular perinatal care had poor outcomes, and the MCDA triplet pregnancy was diagnosed intrapartum.

Conclusions: The possibility of continuing an MCDA triplet pregnancy should be recognized. Early diagnosis, regular antenatal care, close prenatal monitoring, and sufficient communication are recommended to obtain better perinatal outcomes in MCDA triplet pregnancies.
\end{abstract}

Keywords: Monochorionic diamniotic triplet pregnancies, Perinatal outcomes

\section{Background}

Triplet pregnancies are associated with higher fetal morbidity and mortality risk such as to be delivered by cesarean at $<29$ weeks of gestation and to have $>$ or $=1$ infants die as well as life-threatening maternal complications such as preterm premature rupture of membranes, preeclampsia, eclampsia, toxemia, placental abruption, excessive bleeding, to require tocolysis, and postpartum hemorrhage $[1,2]$. The incidence of MCDA triplet births is rare compared to other types of triplet pregnancies [3], and the incidence of spontaneous triplet pregnancies is approximately $1 / 10,000$ [4]. However, triplet births have increased due to older maternal age at conception and the increased use of assisted reproductive technology, such as in vitro fertilization (IVF), intracytoplasmic sperm injection (ICSI), gamete intrafallopian transfer (GIFT), and intracervical insemination (ICI) [5]. The proportion of triplet pregnancies conceived using

\footnotetext{
* Correspondence: fanjy422@163.com

1 Department of Obstetrics and Gynecology, West China Second University

Hospital, Sichuan University, No. 20, 3rd section, South Renmin Road,

Chengdu 610041, Sichuan, China

${ }^{2}$ Key Laboratory of Birth Defects and Related Diseases of Women and

Children (Sichuan University), Ministry of Education, Chengdu, China
}

assisted reproductive technology versus naturally has increased in recent years (42.5\% vs. $17.7 \%)[5,6]$.

Trichorionic triamniotic (TCTA), dichorionic triamniotic (DCTA), and monochorionic triamniotic (MCTA) triplets are the most common types of triplet pregnancies [7]. Monochorionic diamniotic (MCDA) and dichorionic diamniotic (DCDA) triplet pregnancies are extremely rare. Fennessy et al. [8] reported that 58\% (31/ 53), 32\% (17/53), $8 \%(4 / 53)$, and $2 \%(1 / 53)$ of triplet pregnancies are TCTA, DCTA, MCTA, and DCDA, respectively.

Due to special chorionic and amniotic properties in MCDA triplets, cord entanglement between two fetuses can increase the incidence of perinatal morbidity and mortality in MCDA triplets. Nearly 10 papers [7, 9-18] related to MCDA triplet pregnancies have been published so far, and the majority have been case reports. However, there is no consensus-based guidance for the perinatal management of MCDA triplet pregnancies. MCDA triplet pregnancies can have good perinatal outcomes with regular prenatal care. Therefore, the antenatal diagnosis, evaluation, and management of MCDA triplet pregnancies are worth further discussion.

We report three cases of MCDA triplet pregnancies at West China Second University Hospital, a tertiary 
referral center in west China, between January 2012 and December 2017. In addition, we evaluate the perinatal management and outcomes of these MCDA triplets. In our study, the case with regular and intensive prenatal care had a good perinatal outcome, and the case with irregular perinatal care had poor outcomes.

\section{Case presentation}

\section{Case 1}

A 28-year-old nulliparous woman spontaneously conceived a triplet pregnancy and was transferred to our hospital, where she was diagnosed with MCDA triplets at 13 gestational weeks. Ultrasonography revealed MCDA triplets with two of the triplets (triplets A and B) sharing a single amniotic sac. After extensive counseling regarding the potential risks associated with this condition, the couple opted to continue the triplet pregnancy. Regular and thorough ultrasonography was performed weekly after 28 gestational weeks to monitor fetal weight, bladder capacity, amniotic fluid volume, and Doppler blood flow of the fetal umbilical artery, middle cerebral artery, and ductus venosus (DV). Fetal heart rate monitoring by nonstress tests (NSTs) was carried out weekly after 28 weeks of gestation. The couple refused admission until threatened premature labor at 31 weeks and 3 days of gestation. NSTs were performed twice per day, and ultrasonography was performed twice per week. Antenatal steroids were administered to promote fetal maturation. At $32+5$ weeks, an emergency cesarean section was performed due to inevitable preterm labor. The diagnosis of an MCDA triple pregnancy was further confirmed after umbilical cord and histopathological examinations (Fig. 1). Cord entanglement in the monoamniotic pair was diagnosed antenatally and confirmed after umbilical cord examination. The birth weights of the three female newborns were triplet A $1510 \mathrm{~g}$, triplet B $1490 \mathrm{~g}$, and triplet C $1350 \mathrm{~g}$. The 1-min Apgar scores of these three surviving infants were 10,10 , and 9 . The three neonates were transferred to the neonatal intensive care unit (NICU) and were separately discharged from the hospital after 10, 10 and 12 days. None of the triplets had any neurological abnormalities. The mother and the triplets remained in good health during the two and half years of follow-up.

\section{Case 2}

A 27-year-old primipara spontaneously conceived a triplet pregnancy and was transferred to our hospital, where she was diagnosed with an MCDA triplet pregnancy at 18 gestational weeks, with triplets $\mathrm{B}$ and $\mathrm{C}$ sharing a single amniotic sac. The couple opted to continue the pregnancy after extensive counseling. Intensive ultrasonography was performed every week after 28 weeks of gestation. At 29 gestational weeks, the patient was admitted to the hospital. NSTs were performed twice per day, and ultrasonography was performed twice per week. Prophylactic dexamethasone was administered to accelerate fetal lung maturation. At $32+3$ weeks, an emergency cesarean section was performed due to preterm labor. Umbilical cord entanglement between triplets $\mathrm{B}$ and $\mathrm{C}$ was diagnosed antenatally and was confirmed during the operation. Histopathological examination confirmed the placental characteristics of the MCDA triplets (Fig. 2). The birth weights of triplets

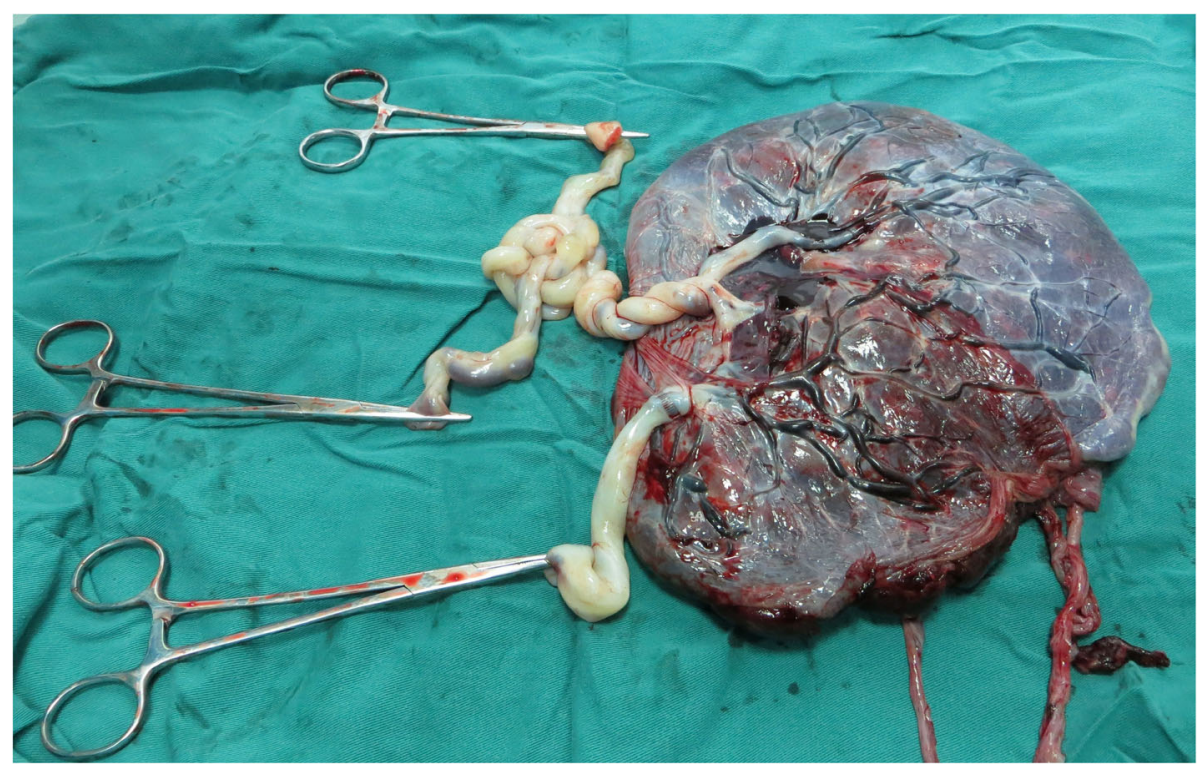

Fig. 1 The placental and umbilical cord examination of case 1 


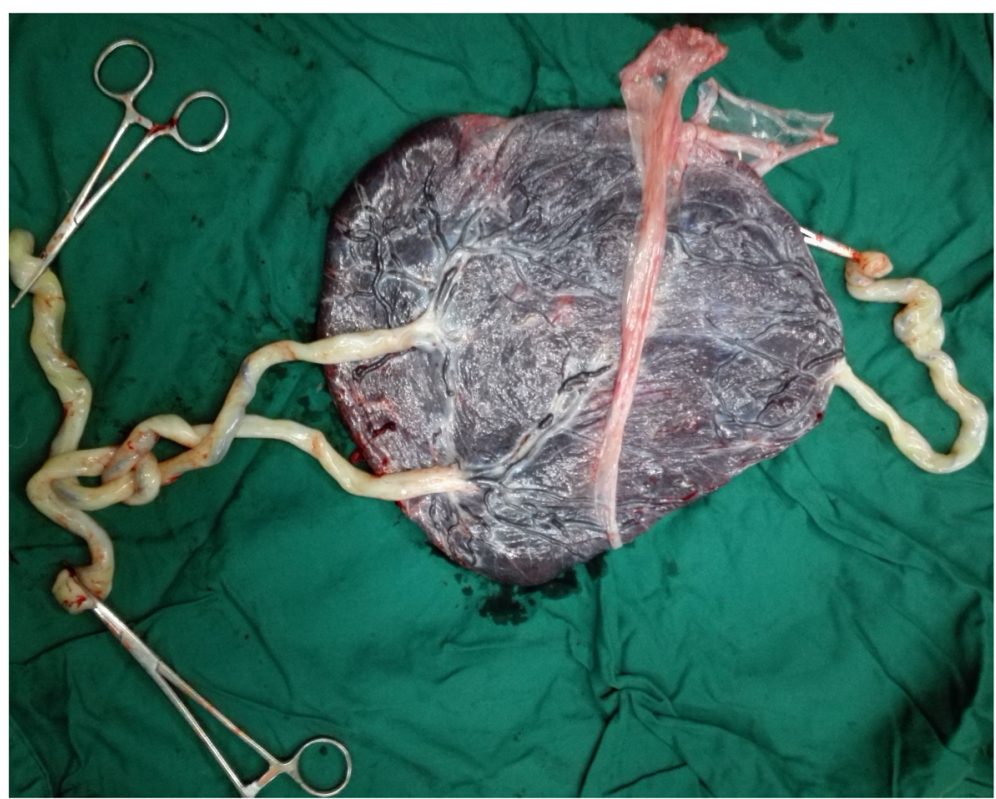

Fig. 2 The placental and umbilical cord examination of case 2

$\mathrm{A}, \mathrm{B}$, and $\mathrm{C}$ were $1750 \mathrm{~g}, 1720 \mathrm{~g}$, and $1830 \mathrm{~g}$, respectively, and the 1-min Apgar scores were 10,10, and 8, respectively. The infants were transferred immediately to the NICU and were discharged after 10, 10 and 19 days. None of the triplets had any neurological abnormalities. The mother and the triplets remained well during the nearly 4 years of follow-up.

\section{Case 3}

A 20-year-old unipara spontaneously conceived a triplet pregnancy and was transferred to our hospital urgently at 28 weeks due to preterm premature rupture of membranes and a serious maternal lung infection. This patient had received no regular care during pregnancy. Antenatal corticosteroids were administered to stimulate fetal lung maturation. An emergency cesarean section was performed at $28+3$ weeks due to maternal acute heart failure complicated with severe pneumonia. Three male newborns were delivered, with triplets A and B sharing an amniotic sac weighing $1000 \mathrm{~g}$ and $900 \mathrm{~g}$, and triplet $\mathrm{C}$ in another amniotic sac weighing $990 \mathrm{~g}$. The diagnosis of an MCDA triplet pregnancy was established by the placenta and umbilical cord examinations and histopathological examination. The 1-min Apgar scores of these three infants were 5,7 , and 7 . The neonates were immediately transferred to the NICU. Triplets A and $\mathrm{B}$ died 23 days after birth, and triplet $\mathrm{C}$ died after 6 days due to multiple organ failure.

\section{Discussion}

Triplet pregnancies are associated with an increased risk of maternal complications, including gestational diabetes mellitus, gestational hypertension, preeclampsia, eclampsia, toxemia, intrahepatic cholestasis of pregnancy, anemia, preterm premature rupture of membranes, placental abruption, excessive bleeding, to require tocolysis, postpartum hemorrhage, and abortion [1, 19-21].

Such pregnancies are also related to poorer neonatal outcomes, such as preterm birth (delivered by cesarean at $<29$ weeks of gestation), intrauterine growth restriction, low birth weight, congenital anomalies, fetal death, and to have $>$ or $=1$ infants die, neurological disability and other short-and long-term disabilities [1, 8, 22]. Besides, the fetal loss rate of triplets is nearly $25 \%$ [23].

The prevalence rate of triplet gestations in the United States and Canada has been approximately 154 and 84 per 100,000 live births, respectively, in the last few years [24]. Moreover, at our hospital, the prevalence rate of triplets was 11.14/10,000, and the proportion of MCDA triplet pregnancies was $4.41 \%$ (3/68) between January 2012 and December 2017.

The placentation of monochorionic is characterized by placental vascular anastomoses and thus inter fetal transfusion [23]. Chorionicity contributes greatly to adverse perinatal outcomes, and monochorionicity is associated with a higher rate of perinatal complications [5]. The rates of fetal death after 22 weeks and neonatal death in MCTA, DCTA, and TCTA triplet pregnancies are $5.3,3.2$, and $2.1 \%$, respectively [25]. In Japan, the perinatal mortality rates of monochorionic, dichorionic, trichorionic triplet deliveries are $12.5,4.4$, and $2.0 \%$, respectively [26]. The incidence of preterm birth before 32 weeks in triplet pregnancies is 24.1-fold higher than that in singleton pregnancies and 3.3-fold higher than 
Table 1 The character of the included study

\begin{tabular}{|c|c|c|c|c|c|c|c|c|c|c|}
\hline Study ID & $\begin{array}{l}\text { Maternal } \\
\text { age } \\
\text { (years) }\end{array}$ & Gravida & Para & $\begin{array}{l}\text { Spontaneously } \\
\text { conceived }\end{array}$ & $\begin{array}{l}\text { Diagnose } \\
\text { weeks }\end{array}$ & $\begin{array}{l}\text { Gestational } \\
\text { age } \\
\text { (weeks) }\end{array}$ & $\begin{array}{l}\text { Delivery } \\
\text { method }\end{array}$ & Maternal complication & Pregnancy outcomes & $\begin{array}{l}\text { Umbilical } \\
\text { cord } \\
\text { entanglement }\end{array}$ \\
\hline $\begin{array}{l}\text { Sepulveda } \\
2003[14]\end{array}$ & 41 & 3 & 2 & not mention & 13 & 28 & CS & No & $\begin{array}{l}\text { Selective feticide of the } \\
\text { conjoined twins was } \\
\text { conducted at } 16 \\
\text { gestational weeks, } \\
\text { the normal triplet } \\
\text { died at } 28 \text { weeks } \\
\text { weighing } 1010 \mathrm{~g}\end{array}$ & Yes \\
\hline $\begin{array}{l}\text { Sepulveda } \\
2009[15]\end{array}$ & 33 & 3 & 1 & not mention & 17 & 31 & CS & No & $\begin{array}{l}\text { Spontaneous cessation } \\
\text { of blood flow to the } \\
\text { acardiac fetus at } 23 \\
\text { weeks, another two } \\
\text { fetuses were alive and well. }\end{array}$ & Yes \\
\hline $\begin{array}{l}\text { Yong } 2010 \\
\text { [11] }\end{array}$ & 32 & 1 & 0 & Yes & $25-26$ & 30 & CS & No & Three healthy triplets & Yes \\
\hline $\begin{array}{l}\text { Youssef } \\
2012[9]\end{array}$ & 22 & 1 & 0 & Yes & 11 & \multicolumn{2}{|l|}{$\begin{array}{l}\text { Termination of } \\
\text { pregnancy }\end{array}$} & No & / & not mention \\
\hline $\begin{array}{l}\text { Sellami } \\
2013[18]\end{array}$ & 20 & 1 & 0 & Yes & 21 & \multicolumn{2}{|l|}{$\begin{array}{l}\text { Termination of } \\
\text { pregnancy }\end{array}$} & No & / & No \\
\hline $\begin{array}{l}\text { Talebian } \\
2015 \text { [16] }\end{array}$ & 38 & 1 & 0 & No (ART) & $12+3$ & 17 & VD & No & $\begin{array}{l}\text { selective feticide of } \\
\text { the conjoined fetuses, } \\
\text { then the membrane } \\
\text { ruptured the day } \\
\text { after the feticide } \\
\text { and inevitable abortion }\end{array}$ & No \\
\hline $\begin{array}{l}\text { Yonetani } \\
2015[7]\end{array}$ & 34 & 1 & 0 & Yes & 12 & 35 & CS & No & Three healthy newborns & Yes \\
\hline $\begin{array}{l}\text { Suizu } 2016 \\
{[10]}\end{array}$ & 34 & 1 & 0 & No (ART) & $8+2$ & 33 & CS & decreased platelet count & $\begin{array}{l}\text { Three healthy and } \\
\text { survival infants }\end{array}$ & Yes \\
\hline $\begin{array}{l}\text { Anglim } \\
2016[17]\end{array}$ & 41 & 1 & 0 & No (ART) & 25 & $30+5$ & CS & $\begin{array}{l}\text { severe hyponatraemia } \\
\text { associated with pre- } \\
\text { eclampsia }\end{array}$ & Three healthy triplets & not mention \\
\hline $\begin{array}{l}\text { May } 2016 \\
{[12]}\end{array}$ & 30 & 2 & 1 & not mention & $\begin{array}{l}\text { Histology of } \\
\text { the } \\
\text { placenta }\end{array}$ & $27+6$ & CS & No & $\begin{array}{l}\text { A live pump twin and } \\
\text { two conjoined acardiac } \\
\text { TRAP recipients }\end{array}$ & No \\
\hline $\begin{array}{l}\text { S Bari. } \\
2018 \text { [13] }\end{array}$ & 25 & 1 & 0 & not mention & $34+$ & $34+$ & CS & respiratory distress & $\begin{array}{l}\text { One alive male fetus } \\
\text { and two female dead fetus }\end{array}$ & No \\
\hline \multicolumn{11}{|l|}{ Our cases } \\
\hline No. 1 & 28 & 3 & 0 & Yes & $13+4$ & $32+5$ & CS & No & $\begin{array}{l}\text { Three healthy and survival } \\
\text { newborns }\end{array}$ & Yes \\
\hline No. 2 & 27 & 3 & 0 & Yes & $18+5$ & $32+3$ & CS & No & $\begin{array}{l}\text { Three healthy and survival } \\
\text { infants }\end{array}$ & Yes \\
\hline No. 3 & 20 & 2 & 0 & Yes & $12+$ & $28+3$ & CS & $\begin{array}{l}\text { lung infection and heart } \\
\text { failure }\end{array}$ & $\begin{array}{l}\text { Three survival male babies, the } \\
\text { parents give up further } \\
\text { treatment }\end{array}$ & Yes \\
\hline
\end{tabular}

CS Cesarean section, VD Vaginal delivery, TRAP Twin reversed arterial perfusion, ART Assisted reproductive technology

that in twin pregnancies [27]. Nearly $14 \%$ of triplets are delivered before 30 weeks, and $61 \%$ of triplets are born before 34 weeks [26]. Compared with singleton pregnancies, triplet pregnancies are nearly four times more expensive [27]. Therefore, triplet pregnancies are not recommended due to higher fetal morbidity and mortality.

When a triplet pregnancy is diagnosed, management options, including continuing the pregnancy with expectant treatment or elective reduction to twins or a singleton, should be discussed with the couple [28, 29]. Elective reduction to twins or a singleton requires occlusion of the umbilical vessel by laser photocoagulation, bipolar electrocoagulation and radiofrequency ablation [30].

When a single embryo splits between 4 and 8 days after fertilization, an MCDA twin pregnancy occurs, and MCTA triplets occur if one of the twins further splits before the 8th day after fertilization [31]. MCDA triplets are extremely rare and can be diagnosed by ultrasonography. Cord entanglement between two fetuses can increase the incidence of perinatal morbidity and mortality in MCDA triplets. Due to the rarity of MCDA triplet pregnancies, there is no standard management protocol.

To the best of our knowledge, there have been nearly 10 papers [7, 9-18] related to MCDA triplet pregnancies 
published in English, and the results are summarized in Table 1.

Most of the cases were diagnosed by ultrasound in the first trimester or early second trimester, especially in Suizu's report [10], where MCDA triplet pregnancies were diagnosed around 9 weeks. Four cases of conjoined twins in MCDA triplet pregnancies have been reported [12, 14, 16, 18]. In May's study, the MCDA triplets consisted of two conjoined acardiac twins and one surviving fetus with a normal heart. The live newborn was delivered by cesarean section at $27+6$ weeks and was discharged from the NICU after a 14.5 -week stay [12]. Two cases were reported of MCDA triplets in which the conjoined twins underwent selective feticide at 16 gestational weeks; however, in one case, intrauterine demise of the normal triplet occurred at 28 weeks [14], and in the other case, the membranes ruptured the day after the procedure, resulting in an inevitable abortion [16]. Sellami's case report [18] describes xipho-omphalopagus conjoined twins in an MCDA triplet pregnancy that was terminated at 21 weeks. Sepulveda [15] reported an acardiac fetus complicating an MCDA triplet pregnancy. The blood flow of the acardiac fetus spontaneously ceased at 23 weeks, while the other two fetuses remained alive and well. Four cases of MCDA triplet pregnancies with regular prenatal care had good perinatal outcomes. These 12 healthy infants remained healthy without any other major complications during follow-up after birth $[7,10,11,17]$. One case with no regular antenatal care was misdiagnosed as a twin pregnancy, and MCDA triplets were established during the cesarean section; one live fetus and two dead fetuses were delivered at 34+ gestational weeks [13]. Detailed information on these cases is provided in Table 1.

In our study, the cases with careful and regular prenatal care had good perinatal outcomes, and six healthy babies remained well without any short-or long-term abnormalities. Conversely, the case (case 3) with no regular antenatal care during pregnancy had a poor outcome.

It is true that some of the conditions discussed from cited papers couldn't be prevented even with regular prenatal care. However, from this data in Table 1, we can see most of the cases were diagnosed by ultrasound in the first trimester or early second trimester and conjoined twins were common in MCDA triplets. Besides, we also can see that for most MCDA triplet pregnancies with regular prenatal care had good perinatal outcomes expect some uncontrollable and unavoidable factors.

\section{Conclusion}

Taking together the above-published articles and our cases, we conclude that intensive prenatal care by a multidisciplinary team is important for obtaining a better perinatal outcome. In addition, umbilical cord entanglement between two fetuses sharing the same amniotic sac was found in most of our MCDA triplets, which can increase the incidence of perinatal morbidity and mortality. MCDA triplet pregnancies with cord entanglement can be successfully managed by early diagnosis, regular antenatal care, close prenatal monitoring, sufficient communication, and elective delivery.

Therefore, it is very important for women with an MCDA triplet pregnancy to obtain intensive prenatal care, which can help obstetricians adjust perinatal evaluations and management strategies in a timely manner to avoid adverse perinatal complications. Weekly ultrasounds are recommended after 28 gestational weeks. It is better for women with MCDA triplet pregnancies to be admitted to the hospital at 28-30 weeks and complete fetal lung maturation. A histopathological examination of the placenta to confirm the chorionicity and amnionicity of an MCDA triplet pregnancy is necessary after delivery.

\section{Abbreviations \\ CS: Cesarean section; DCDA: Dichorionic diamniotic; DCTA: dichorionic triamniotic; DV: Ductus venosus; MCDA: Monochorionic diamniotic; MCTA: Monochorionic triamniotic; NICU: Neonatal intensive care unit; NST: Nonstress testing; TCTA: Trichorionic triamniotic; TRAP: Twin reversed arterial perfusion}

\section{Acknowledgments}

We are grateful for the doctors and staff who have been involved in this work.

\section{Authors' contributions}

TX carried out the retrospective review of the cases and participated in writing and organizing the manuscript. XW participated in the design of the study. HY conceived the study and its design and revised the manuscript. XL participated in the manuscript revision. All authors read and approved the final manuscript.

\section{Funding}

This study was supported by the Academic and Technical Leader's Foundation of Sichuan Province (No.2017-919-25) and the Science Foundation of Sichuan Province (2018FZ0041). The role of these grants was to support the extensive literature search.

\section{Availability of data and materials \\ The data set supporting the conclusions of this article is included in the article.}

Ethics approval and consent to participate

This study was approved by the Institutional Review Board of West China Second University Hospital.

\section{Consent for publication}

Written informed consent was obtained from the patients for publication of this case report and any accompanying images. A copy of the written consent is available for review by the Editor of this journal.

Competing interests

The authors declare that they have no competing interests. 
Received: 16 August 2019 Accepted: 26 November 2019

Published online: 11 December 2019

\section{References}

1. Luke $B$, Brown MB. Maternal morbidity and infant death in twin vs triplet and quadruplet pregnancies. Am J Obstet Gynecol. 2008;198(4):401.e1-10.

2. Boulot P, Hedon B, Pelliccia G, Peray P, Laffargue F, Viala JL. Effects of selectivereduction in triplet gestation: a comparative study of 80 cases managed with or without this procedure. Fertil Steril. 1993:60(3):497-503.

3. Myrianthopoulos NC. An epidemiologic survey of twins in a large, prospectively studied population. Am J Hum Genet. 1970;22(6):611-29.

4. Ho ML, Chen JY, Ling UP, Chen JH, Huang CM, Chang CC, et al. Changing epidemiology of triplet pregnancy: etiology and outcome over twelve years. Am J Perinatol. 1996;13(5):269-75.

5. Committee on Practice Bulletins-Obstetrics. Practice bulletin no. 169: multifetal gestations: twin, triplet, and higher-order multifetal pregnancies. Obstet Gynecol. 2016;128(4):e131-46.

6. Reynolds MA, Schieve LA, Martin JA, Jeng G, Macaluso M. Trends in multiple births conceived using assisted reproductive technology, United States, 1997-2000. Pediatrics. 2003:111(5 Pt 2):1159-62.

7. Yonetani N, Ishii K, Mabuchi A, Sasahara J, Hayashi S, Mitsuda N. Prenatally diagnosed monochorionic diamniotic triplet pregnancy. J Obstet Gynaecol Res. 2015;41(8):1266-8

8. Fennessy KM, Doyle LW, Naud K, Reidy K, Umstad MP. Triplet pregnancy: is the mode of conception related to perinatal outcomes? Twin Res Hum Genet. 2015:18(3):321-7.

9. Youssef A, Milano V, Pilu G, Pelusi G, Ghi T. Three-dimensional sonograph of a monochorionic diamniotic triplet pregnancy. J Clin Ultrasound. 2012;40(4): 227-30.

10. Suizu A, Sato Y, Maruyama S, Nakaki A, Satake $Y$, Mise H, et al. Successful management of monochorionic diamniotic triplet pregnancy. J Obstet Gynaecol. 2016;36(6):758-9.

11. Yong PJ, Farquharson DF, Ubhi J. Monochorionic diamniotic triplet pregnancy with prenatal diagnosis of cord entanglement. J Obstet Gynaecol Can. 2010;32(3):274-7.

12. May JS, Lanni S, Jakowski JD. A case of twin reversed arterial perfusion (TRAP) sequence in a monochorionic diamniotic triplet pregnancy with two acardiac fetuses. Int J Diagn Imaging. 2016;3(2):59-64.

13. Bari S, Sanjida K, Tania A, Shabnam R. Monochorionic diamniotic triplets and role of obstetric ultrasound. EC Gynaecol. 2018;7(2):52-6.

14. Sepulveda W, Munoz H, Alcalde JL. Conjoined twins in a triplet pregnancy: early prenatal diagnosis with three-dimensional ultrasound and review of the literature. Ultrasound Obstet Gynecol. 2003;22(2):199-204.

15. Sepulveda W, Wong AE, Bustos JC, Flores X, Alcalde JL. Acardiac fetus complicating a triplet pregnancy: management and outcome. Prenat Diagn. 2009;29(8):794-9.

16. Talebian M, Rahimi-Sharbaf F, Shirazi M, Teimoori B, Izadi-Mood N, Sarmad S. Conjoined twins in a monochorionic triplet pregnancy after in vitro fertilization: a case report. Iran J Reprod Med. 2015;13(11):729-32.

17. Anglim B, Levins K, Bussmann N, Imcha M. Severe hyponatraemia associated with pre-eclampsia. BMJ Case Rep. 2016;2016:bcr2016215036.

18. Sellami A, Chakroun N, Frikha R, Bouayed NA, Amouri H, Rebai T. Xiphoomphalopagus conjoined twins in a spontaneous triplet pregnancy: autopsy findings. APSP J Case Rep. 2013;4(3):49.

19. O'Donoghue K, Barigye O, Pasquini L, Chappell L, Wimalasundera RC, Fisk NM. Interstitial laser therapy for fetal reduction in monochorionic multiple pregnancy: loss rate and association with aplasia cutis congenita. Prenat Diagn. 2008;28(6):535-43

20. Wen SW, Demissie K, Yang Q, Walker MC. Maternal morbidity and obstetric complications in triplet pregnancies and quadruplet and higher-order multiple pregnancies. Am J Obstet Gynecol. 2004;191(1):254-8.

21. Sattar N, Greer IA. Pregnancy complications and maternal cardiovascular risk: opportunities for intervention and screening? BMJ. 2002;325(7356):15760

22. Lewi L, Gratacos E, Ortibus E, Van Schoubroeck D, Carreras E, Higueras T, Perapoch J, Deprest J. Pregnancy and infant outcome of 80 consecutive cord coagulations in complicated monochorionic multiple pregnancies. Am J Obstet Gynecol. 2006;194(3):782-9.

23. Fell DB, Joseph K. Temporal trends in the frequency of twins and higherorder multiple births in Canada and the United States. BMC Pregnancy Childbirth. 2012;12:103
24. Alexander GR, Kogan M, Martin J, Papiernik E. What are the fetal growth patterns of singletons, twins, and triplets in the United States? Clin Obstet Gynecol. 1998;41(1):114-25.

25. Kawaguchi H, Ishii K, Yamamoto R, Hayashi S, Mitsuda N. Perinatal death of triplet pregnancies by chorionicity. Am J Obstet Gynecol. 2013;209(1):36.e1-

26. Morikawa M, Cho K, Yamada T, Yamada T, Sato S, Minakami H. Clinical features and short-term outcomes of triplet pregnancies in Japan. Int J Gynaecol Obstet. 2013;121(1):86-90.

27. Weissman A, Ulanovsky I, Burke Y, Makhoul IR, Blazer S, Drugan A. Triplet pregnancies--a three-decade perspective: do we fare better? Eur J Obstet Gynecol Reprod Biol. 2013;170(1):82-4.

28. Chaveeva P, Kosinski P, Puglia D, Poon LC, Nicolaides KH. Trichorionic and dichorionic triplet pregnancies at 10-14 weeks: outcome after embryo reduction compared to expectant management. Fetal Diagn Ther. 2013; 34(4):199-205.

29. Chaveeva P, Kosinski P, Birdir C, Orosz L, Nicolaides KH. Embryo reduction in dichorionic triplets to dichorionic twins by intrafetal laser. Fetal Diagn Ther. 2014;35(2):83-6.

30. Roman A, Papanna R, Johnson A, Hassan SS, Moldenhauer J, Molina S, et al. Selective reduction in complicated monochorionic pregnancies: radiofrequency ablation vs. bipolar cord coagulation. Ultrasound Obstet Gynecol. 2010;36(1):37-41.

31. Li Y, Yang D, Zhang $Q$. Dichorionic quadramniotic quadruple gestation with monochorionic triamniotic triplets after two embryos transfer and selective reduction to twin pregnancy: case report. Fertil Steril. 2009:92(6):2038.e13-5.

\section{Publisher's Note}

Springer Nature remains neutral with regard to jurisdictional claims in published maps and institutional affiliations.

Ready to submit your research? Choose BMC and benefit from:

- fast, convenient online submission

- thorough peer review by experienced researchers in your field

- rapid publication on acceptance

- support for research data, including large and complex data types

- gold Open Access which fosters wider collaboration and increased citations

- maximum visibility for your research: over $100 \mathrm{M}$ website views per year

At BMC, research is always in progress.

Learn more biomedcentral.com/submissions 